\title{
Correction to: Microstructural evolution and room temperature mechanical properties of AZ31 alloy processed through hot constrained compression
}

\author{
Amir Ghorbani ${ }^{1} \cdot$ Abbas Zarei-Hanzaki ${ }^{1} \cdot$ Pooriya Dastranjy Nezhadfar ${ }^{1}$ (D) $\cdot$ Mohammad Hadi Maghsoudi $^{1}$
}

Published online: 23 February 2019

(C) Springer-Verlag London Ltd., part of Springer Nature 2019

\section{Correction to: The International Journal of Advanced Manufacturing Technology \\ https://doi.org/10.1007/s00170-019-03321-0}

The original version of this article contained a mistake.

Regrettably, the first names of the first and second author were interchanged. Their names are now correctly shown above.

The original article has been corrected.

Publisher's note Springer Nature remains neutral with regard to jurisdictional claims in published maps and institutional affiliations.

The online version of the original article can be found at https://oi.org/ 10.1007/s00170-019-03321-0

\footnotetext{
Abbas Zarei-Hanzaki

zareih@ut.ac.ir

1 The Complex Laboratory of Hot Deformation \& Thermo-mechanical Processing of High Performance Engineering Materials, School of Metallurgy and Materials Engineering, College of Engineering, University of Tehran, Tehran, Iran
} 